\title{
The silent epidemic of falls from buildings: analysis of risk factors
}

\author{
Lena Mayer · Martin Meuli · Ulrich Lips · \\ Bernhard Frey
}

Accepted: 4 July 2006/ Published online: 27 July 2006

(C) Springer-Verlag 2006

\begin{abstract}
This study wanted to search for potential risk factors associated with falls from windows and balconies in order to eventually improve prevention. All children under the age of 16 years suffering from head injuries/multiple trauma due to falls from windows or balconies treated over the last 7 years at the intensive care unit (ICU) of the University Children's Hospital Zürich were analysed retrospectively (group A). Fifty patients out of all children suffering from head injuries/multiple trauma due to other types of accidents in the same period were selected at random as controls (group B). Out of a total of 241 children with head injury and/or multiple trauma, $31(13 \%)$ fell out of a building. Twenty-seven of these victims (87\%) fell from the third floor or lower. Twenty-one of the falls $(68 \%)$ occurred at home. Fifteen children (49\%) climbed on a piece of furniture before falling. In almost $20 \%$ of the accidents dangerous balcony or house constructions led to the fall. Parents did not witness the fall, except for three cases $(10 \%)$ with direct parental involvement (one mother jumped out with her child, two mothers threw their child out of the window). Two children $(6 \%)$ attempted suicide. Children aged 0
\end{abstract}

L. Mayer · B. Frey $(\square)$

Department of Intensive Care and Neonatology,

University Children's Hospital, Zürich 8032, Switzerland

e-mail: Bernhard.Frey@kispi.unizh.ch

M. Meuli

Department of Surgery, University Children's Hospital,

Zürich, Switzerland

U. Lips

Child Protection group, University Children's Hospital,

Zürich, Switzerland
5 years were predominantly represented $(84 \%)$, and all six children who died were in this age group. There were significantly more patients with foreign nationalities and lower socio-professional categories in group A than in group B. In both groups, the accidents concerned the youngest child of the family in approximately $50 \%$ and happened mostly during summer evenings. There were no significant differences in injured systems and in injury severity between the two groups. This study identified young age, an immigrant family setting, low socio-professional category of the parents, dangerous house constructions, inappropriate furniture placement, and summertime evenings as risk factors for serious building falls in children. This information may foster focused prevention.

Keywords Fall · Building · Severe injury · Children · Prevention

\section{Introduction}

Falls are a leading cause of morbidity and mortality in children [1-4]. Different studies report that falls from windows and balconies are not insignificant [1-8]. According to the Swiss Advisory Board for Accident Prevention (BFU), every second accident of a child in Switzerland is a fall occurring mostly at home and in leisure time; especially falls from heights $(25 \%$ of all falls) such as falls from windows result in serious injuries [9]. The most frequent injuries are head injuries followed by fractures of the extremities [1-4, 8]. Head injuries are responsible for the associated mortality $[1,4]$. Data of the BFU show that falls are 
ranking third after traffic and suffocation accidents as a cause of accidental death in children [9].

Falls from windows and balconies happen in the majority of cases unintentionally $[4,7]$. To avoid such falls preventive measures should be improved by investigating the causes and the circumstances of these accidents. The health education program "Children cannot fly" in New York City in the seventies drastically reduced the frequency of falls from windows and may serve as an example for prevention programs in Switzerland [10].

With this study we were aiming to determine the risk profile of children suffering from head injuries/ multiple trauma due to falls from windows or balconies in order to improve preventive measures.

\section{Patients and methods}

This retrospective review over a 7-year-period (1 June 1998-31 May 2005) includes children from 0 to $\leq 16$ years of age suffering from head injuries and/or multiple trauma due to falls from windows or balconies and treated at the intensive care unit (ICU) of the University Children's Hospital Zürich, Switzerland. These children constitute group A. Multiple trauma refers to injuries of two or more parts of the body (head, thorax, abdomen, urogenital, extremities/spinal column/pelvis).

Data extracted from patient records included number of fall victims, height (floor), site of accident (window or balcony, at home or away from home), particularities in constructions and installations of the flat or the house, surface of impact, whether the falls were observed by testimonies, time of day, season, demographical factors (age, sex, nationality, age of brothers and sisters, profession and age of the parents), type of injuries (head, thorax, abdomen, urogenital, extremities/spinal column/pelvis), glasgow coma scale (GCS) at the scene, markers of injury severity [intracranial pressure (ICP), length of artificial ventilation, length of ICU- and hospital-stay, need for treatment in a rehabilitation centre and mortality], medical history, findings of the Child Protection Group. The socioprofessional status of fathers and mothers was categorised according to the definitions of the Swiss Federal Office of Statistics [11].

For selected comparisons a control group (group B) of 50 children out of all 210 children suffering from head injuries/multiple trauma due to other types of accidents and treated during the same time period and at the same ICU was selected at random. These children were victims of other kinds of falls (20 cases), traffic accidents (19), agriculture accidents (4), sport accidents (4), fights (1), bullet wounds (1), or they were smashed by an object (1).

Statistics: Data are given as proportions and medians with their ranges. Categorical data were analysed with Chi-square test (Yates corrected) or Fisher's exact test. Continuous data were analysed with Wilcoxon rank sum test. Statistical calculations were performed with STATA Version 9.1 (Stata Corp, College Station, TX, USA). A $P$ value less than 0.05 was considered statistically significant. 50 children were selected as controls by independent random variables out of a cohort of 210 (S-Plus, Insightful, Seattle, USA).

\section{Results}

Circumstances of falls

During the 7 years analysed, 241 children had been treated at the ICU for head injuries/multiple trauma. Of these, 31 (13\%) children (group A) fell from a window (15 cases), a balcony (13), a roof (1), or a door (1). In one case the exact mechanism of the fall was unclear, however, the child had fallen out of a building. Fourteen children $(45 \%)$ fell from the first floor, seven children from the second floor, six from the third floor, one from the fourth floor, two from the fifth floor and one from the ninth floor. The children impinged on concrete (16 cases), grassland, grit, or small bushes (3) or were slowed down by a roof, canopy, or shutter (6) or a person (2) (unknown 4). Twenty-one of the falls occurred at home $(68 \%)$ whereas only nine of these accidents happened away from home (29\%) (unknown 1).

In seven accidents $(23 \%)$ there was a chair, a bed, or bedside table, a sofa or a ledge in front of the window allowing the children to move up. Eight fall victims $(26 \%)$ had the possibility to climb on a chair or a dustbin which was standing on the balcony. Dangerous balcony constructions caused five accidents $(16 \%)$ ). One child fell out of a door which was located on the first floor, leading directly out of the building and which was usually locked. In three other incidents $(10 \%)$ parents were directly involved in the falls: one mother jumped out of the window with her child because of fire in the flat and two mothers threw their child out of the window. Two children attempted suicide. In five cases $(16 \%)$ no risk factor could be identified. In 13 children (42\%) nobody took note of the fall, whereas in 16 cases $(52 \%)$ somebody witnessed the accident. In two cases, it is unknown whether the fall was observed. Testimonies of the falls 
were sisters and brothers or other children (6 cases), relatives (3), pedestrians or neighbours (4). In the three accidents where parents were present, they had been also directly responsible for the fall (see above). The Child Protection Group interfered in nine cases (indeed one case was released to another hospital). A "referral to Child Welfare System" occurred in four cases; another four cases were categorised as accidents and no child protection measures were implemented.

There were no significant differences in time of day and season between group A (balcony/window falls) and group B (other accidents). The peaks of both groups were in summertime and in the evening. Forty-five percent and $40 \%$ of the accidents in group A and B happened in summer and 29 and $36 \%$ of the accidents in group A and B happened in the evening (18-22 pm). Time of day is unknown for each $26 \%$ of cases in group A and $\mathrm{B}$.

In group A one child was hyperactive, all other case histories were inconspicuous. In group B there was one child with microdeletion $22 \mathrm{q} 11$, one with autosomal recessive polycystic kidney disease, one with trisomy 21 , and one with chronic immuncytopenia.

\section{Demographics}

The difference in age between group A and group B was highly significant (Table 1 ). The highest rate of falls from windows and balconies occurred in infants $0-5$ years of age $(84 \%)$, and all children who died
(6 children, 19\%) were in this age group (significant difference in mortality for children $\leq 5$ years between group $\mathrm{A}$ and $\mathrm{B}, P=0.01$, Table 2 ). In contrast, the ages of the children of group B were evenly distributed. The parents' ages were not significantly different between group A and B (Table 1). There were more boys in both groups (Table 1). More foreign nationalities were represented in group A $(68 \%)$ than in group B $(12 \%)(P<0.0001)$ (Table 1$)$. In both groups, the youngest child of the family was mainly affected (percentage of cases in group A and B: youngest child of the family 55 and $48 \%$, middle position 7 and $10 \%$, oldest child 16 and $26 \%$, only child 7 and $10 \%$; patient position is unknown for $16 \%$ of cases in group A and $6 \%$ of cases in group B). The differences in the socioprofessional categories of fathers and mothers between group A and B were highly significant $(P<0.001$ and $P<0.01)$. Fully qualified and currently employed fathers were much less represented in group A than in group B (48 and 82\%, respectively). Unemployed fathers were only found in group A. Fully qualified mothers were also much less represented in group A than in group B (26 and 60\%, respectively).

\section{Injuries and injury severity}

There were no significant differences in injured body regions and injury severity between the two groups (Table 2).

Table 1 Demographics

\begin{tabular}{|c|c|c|c|c|c|c|}
\hline & \multicolumn{3}{|c|}{ Group A (balcony/window falls) } & & \multicolumn{2}{|c|}{ Group B (other accidents) } \\
\hline & Median & & Range & & Median & Range \\
\hline \multicolumn{7}{|l|}{ Age (years) } \\
\hline Child $^{\mathrm{a}}$ & 2.6 & & $0-13.6$ & & 6.7 & $0.4-16.4$ \\
\hline Father $^{\mathrm{b}}$ & 35 & & $23-50$ & & 40.5 & $28-63$ \\
\hline \multirow[t]{2}{*}{ Mother $^{\mathrm{b}}$} & 31 & & $18-42$ & & 36.0 & $24-48$ \\
\hline & & No & & $\%$ & No & $\%$ \\
\hline \multicolumn{7}{|l|}{ Sex } \\
\hline Female & & 13 & & 41.9 & 18 & 36.0 \\
\hline Male & & 18 & & 58.1 & 32 & 64.0 \\
\hline \multicolumn{7}{|l|}{ Nationality $^{\mathrm{c}}$} \\
\hline Switzerland & & 10 & & 32.3 & 44 & 88.0 \\
\hline Abroad & & 21 & & 67.7 & 6 & 12.0 \\
\hline Region of Balkan & & 11 & & 35.5 & 2 & 4.0 \\
\hline Africa & & 3 & & 9.7 & 1 & 2.0 \\
\hline Asia & & 6 & & 19.4 & 2 & 4.0 \\
\hline Remaining Europe & & 1 & & 3.2 & 1 & 2.0 \\
\hline
\end{tabular}


Table 2 Markers of injury severity and injured body regions (head injury and/or multiple trauma was an inclusion criterion)

\begin{tabular}{|c|c|c|c|c|}
\hline & \multicolumn{2}{|c|}{$\begin{array}{l}\text { Group A (balcony/window } \\
\text { falls) }\end{array}$} & \multicolumn{2}{|c|}{ Group B (other accidents) } \\
\hline & Median & Range & Median & Range \\
\hline Glasgow coma scale (GCS) & 8.0 & $3-15$ & 9.0 & $3-15$ \\
\hline Peak intracranial pressure (ICP) above $20(\mathrm{mmHg})$ & 38.5 & $22-117$ & 45.0 & $21-114$ \\
\hline Length of mechanical ventilation (days) ${ }^{\mathrm{a}}$ & 2.0 & $1-7$ & 2.0 & $1-17$ \\
\hline Length of ICU stay (days) & 2.0 & $1-8$ & 2.5 & $1-19$ \\
\hline \multirow[t]{2}{*}{ Length of hospital stay (days) } & 7.0 & $1-78$ & 9.5 & $1-46$ \\
\hline & No & $\%$ & No & $\%$ \\
\hline Intracranial pressure measurement ${ }^{\mathrm{b}}$ (cases) & 14 & 45.2 & 26 & 52.0 \\
\hline ICP above $20 \mathrm{mmHg}$ (cases) & 12 & 38.7 & 19 & 38.0 \\
\hline Artificial ventilation (cases) & 18 & 58.1 & 36 & 72.0 \\
\hline Mortality (cases) & 6 & 19.4 & 6 & 12.0 \\
\hline Mortality $\leq$ 5years $(\text { cases })^{\mathrm{c}}$ & 6 & 19.4 & 1 & 2.0 \\
\hline Mortality $\geq 5$ years (cases) $^{\mathrm{c}}$ & 0 & 0.0 & 5 & 10.0 \\
\hline Rehabilitation centre & 4 & 12.9 & 6 & 12.0 \\
\hline Head & 31 & 100.0 & 50 & 100.0 \\
\hline Thorax & 11 & 35.5 & 9 & 18.0 \\
\hline Extremities, Spinal column, Pelvis & 9 & 29.0 & 9 & 18.0 \\
\hline Abdomen & 5 & 16.1 & 5 & 10.0 \\
\hline Urogenital & 1 & 3.2 & 2 & 4.0 \\
\hline
\end{tabular}

${ }^{a}$ Unknown: group B: one case

${ }^{\mathrm{b}}$ Unknown: group A: one case

${ }^{\mathrm{c}} P=0.01$, Fisher's exact test

\section{Discussion}

Our findings show that falls from windows and balconies with severe sequelae mainly happen to boys of foreign nationality, $0-5$ years old, when climbing furniture, at home, in the evening, during summertime.

Previous studies correspond with our results that young children $0-5$ years old have a significant higher rate of falls from heights than children aged 5-16 years old [1-8]. Our study as well as others clearly shows that infants are much more likely to die from a fall than older children $[1,5]$. The main reason of this peak in early childhood may be the steadily increasing mobility and curiosity to explore the environment without an equally developed risk behaviour. Therefore infants require close attendance by their caregivers. Boys may need even more attention because they usually have different risk behaviours and other playing habits than girls. Different studies confirm our results that boys fall more frequently from heights than girls $[2-4,6-8]$. We further found that in about $50 \%$ of the analysed accidents the youngest child of the family was the victim. Reasons for this result could be that younger children imitate their brothers and sisters, that parents are overstrained with several children, or that parents put too much responsibility on their other children for looking after the youngest sibling. Further on, parents may become less and less careful with every further child.

Regarding site safety issues, furniture was imprudently placed: almost $50 \%$ of the fall victims had the possibility to climb a piece of furniture. Caregivers did not consider the potential risks of places unknown and interesting for their children. Most of the falls occurred at home. This finding is confirmed by other studies [3, 4]. It may reflect a tighter supervision at foreign places than at home. In our survey unfavourable balcony or house constructions led to the fall in almost $20 \%$. This correlates with different studies where the lack of windows and balconies code regulations are highlighted as one of the reasons [2,6]. In Switzerland balustrade and handrail constructions often do not conform to the guidelines of the Swiss Engineers and Architects Association [12]. However, it is well proven that suitable technical construction measures beware a considerable number of accidents [12].

Excluding the three cases with direct parental involvement causing the falls, the parents or the supervising person did not see the fall of the child. This means that the child was left alone at home (four times) or left unattended for a short time, with or without the presence of brothers and sisters.

In our study most accidents in both groups happened during summertime, fewer in spring and 
autumn, and hardly any during winter. This correlates with previous reports [2,3]. During the warm seasons people are more likely to leave windows and balcony doors open. The reasons why accidents in our and other surveys [2] mainly happened in the evening may be that family members are busy with meal preparation at this time or that they are distracted by all children being around.

We were most surprised by the finding that the majority of fall victims $(68 \%)$ had a foreign nationality. Causes could be different risk awareness and behaviour, unclear responsibilities in a big family circle, or different mentality and rules. Further on, the dominant role of the man in contrast to the often lower role of the woman in several nationalities could make children disobey their mother. In our survey, $36 \%$ of the fall victims were of Balkan-nationality, possibly including grandchildren of the refugees from the Balkan War in the early nineties. A study from the USA showed that black children were more likely to fall out of windows than non-black children [7]. In another survey race or ethnicity were of no significant influence [2].

A further interesting aspect in our survey is the fact that the professional qualification of fathers and mothers was significantly lower in group A (balcony/window falls) than group B (other accidents). On the one hand this could be based on the high fraction of foreign families in our study. Foreigners often have worse conditions and chances to get an equal job training. On the other hand these families may not dispose of sufficient educational and financial capabilities for protection measures. Further, they often live in high-rise buildings and both parents need to work for survival. Socioeconomic poverty as a cause of falls was evident in a study [13], whereas it was not in another one [14].

Concerning child protection issues of falls from buildings, the local Child Protection Group should be involved on a low threshold, because these accidents must be treated as potential neglect on the part of the caregivers.

The Swiss Advisory Board for Accident Prevention (BFU) provides information about accident prevention and protection measures to architects, property managements, communities and individuals. "The BFU-childmail" (bfu-Kinderpost) informs 200,000 parents every half year how to protect young children $\leq 6$ years against accidents [15]. However, this BFUchildmail is only sent to parents with first born babies which possibly should be reviewed considering the fact that mainly the youngest child of the family was the victim in our survey. Information about fall prevention is only highlighted for children up to 2.5 years [15], however, we showed that falls from heights concern as well children up to 5 years of age. Furthermore, it is doubtful that this German-written information is read by foreign-language families (the BFU-childmail is translated into the three national languages German, French and Italian). Translations into other languages should be performed. Beside these improvements, media campaign to elevate the public awareness of this hazard, individual parent education to highlight the possible risks, door-to-door hazard identifications, and contact points are possibilities to protect vulnerable families. Many studies reinforce the need of childhood injury protection and suggest improved prevention tools such as window guards, home safety programs, and national laws [10, 16-20].

In conclusion, this study identified young age, an immigrant family setting, low socio-professional category of the parents, dangerous house constructions, inappropriate furniture placement, and summertime evenings as risk factors for serious building falls. This information may foster focused prevention.

Acknowledgments This study was supported by a grant from the Swiss Advisory Board for Accident Prevention (BFU).

\section{References}

1. Hall JR, Reyes HM, Horvat M, Meller JL, Stein R (1989). The mortality of childhood falls. J Trauma 29:1273-1275

2. Istre GR, Mc Coy MA, Stowe M, Davies K, Zane D, Anderson RJ, Wiebe R (2003) Childhood injuries due to fall from apartment balconies and windows. Inj Prev 9:349-352

3. Lallier M, Bouchard S, St-Vil D, Dupont J, Tucci M (1999) Falls from heights among children: a retrospective review. J Pediatr Surg 34:1060-1063

4. Wang MY, Kim KA, Griffith PM, Summers S, McComb JG, Levy ML, Mahour GH (2001) Injuries from falls in the pediatric population: an analysis of 729 cases. J Pediatr Surg 36:1528-1534

5. Benoit R, Watts DD, Dwyer K, Kaufmann C, Fakhry S (2000) Windows 99: a source of suburban pediatric trauma. J Trauma 49:477-481

6. Lehman D, Schonfeld N (1993) Falls from heights: a problem not just in the northeast. Pediatrics 92:121-124

7. Stone KE, Lanphear BP, Pomerantz WJ, Khoury J (2000) Childhood injuries and deaths due to falls from windows. J Urban Health 77:26-33

8. Vish NL, Powell EC, Wiltsek D, Sheehan KM (2005) Pediatric window falls: not just a problem for children in high rises. Inj Prev 11:300-303

9. bfu Schweizerische Beratungsstelle für Unfallverhütung (2003) Stürze zu Hause '03. Bfu-Handbuch. Bern, http:// www.bfu.ch/handbuch/index.html

10. Spiegel CN, Lindaman FC (1977) Children can't fly: a program to prevent childhood morbidity and mortality from window falls. Am J Public Health 67:1143-1147

11. Bundesamt für Statistik (2005) Volkszählung $>$ Kennzahlen > Sozioprofessionelle Kategorien. Neuchâtel, http://www.bfs. admin.ch/bfs/portal/de/index/themen/volkszaehlung/uebersicht/ blank/kennzahlen0/sozio_professionelle_kategorien.html 
12. bfu Schweizerische Beratungsstelle für Unfallverhütung (2003) Geländer und Brüstungen; Basis sia-Norm 358. BfuHandbuch, Bern, http://www.bfu.ch/handbuch/index.html

13. Faelker T, Pickett W, Brison RJ (2000) Socioeconomic differences in childhood injury: a population based epidemiologic study in Ontario, Canada. Inj Prev 6:203-208

14. Carter YH, Jones PW (1993) Accidents among children under five years old: a general practice based study in north Staffordshire. Br J Gen Pract 43:159-163

15. Bfu Schweizerische Beratungsstelle für Unfallverhütung (2005) Bfu-Kinderpost:1-5. Bern, 2005

16. Dowswell T, Towner EM, Simpson G, Jarvis SN (1996) Preventing childhood unintentional injuries-what works? A literature review. Inj Prev 2:140-149

17. Jordaan ER, Atkins S, van Niekerk A, Seedat M (2005) The development of an instrument measuring unintentional injuries in young children in low-income settings to serve as an evaluation tool for a childhood home injury prevention program. J Safety Res 36:269-280

18. King WJ, LeBlanc JC, Barrowman NJ, Klassen TP, BernardBonnin AC, Robitaille Y, Tenenbein M, Pless IB (2005) Long term effects of a home visit to prevent childhood injury: three year follow up of a randomized trial. Inj Prev 11:106-109

19. McClure R, Nixon J, Spinks A, Turner C (2005) Communitybased programmes to prevent falls in children: a systematic review. J Paediatr Child Health 41:465-470

20. Towner E, Dowswell T, Jarvis S (2001) Updating the evidence. A systematic review of what works in preventing childhood unintentional injuries: Part 2. Inj Prev 7:249-253 